\title{
Estudio semántico-cognitivo del neologismo pedalista en la variante del español de Colombia
}

\author{
Mercedes SuÁrez de la Torre \\ Coordinadora del Doctorado en \\ Ciencias Cognitivas y líder del Grupo \\ de Investigación CITERM (Centro de \\ Investigación Terminológica) \\ Universidad Autónoma de Manizales \\ Antigua Estación del Ferrocarril \\ Manizales - Caldas - Colombia \\ E-mail: \\ mercedessuarez@autonoma.edu.co \\ Diana Lorena Giraldo Ospina \\ Docente-investigador del Grupo \\ de Investigación CITERM (Centro \\ de Investigación Terminológica) \\ Universidad Autónoma de \\ Manizales \\ Antigua Estación del Ferrocarril \\ Manizales - Caldas - Colombia \\ E-mail: \\ dgiraldo@autonoma.edu.co
}

\section{ESTUDIO SEMÁNTICO-COGNITIVO DEL NEOLOGISMO PEDALISTA EN LA VARIANTE DEL ESPAÑOL DE COLOMBIA}

RESUMEN: Este estudio presenta un análisis semántico-cognitivo del neologismo pedalista cuya formación se da a partir de uno de los sufijos más predominantes en la variante del español de Colombia. En primer lugar, se identificaron y clasificaron los neologismos formados por sufijación, sistematizados por la Antena Neológica Colombiana (ANECOL), de los ejemplares digitales del periódico El Tiempo del año 2014. Posteriormente, se estableció que -ista era el sufijo con mayor número de ocurrencias. Finalmente, se realizó un análisis semántico-cognitivo del neologismo pedalista desde la Teoria de los Espacios Mentales (Fauconnier, [1985] (1994)) y la Integración Conceptual (Fauconnier y Turner, 2001). Los resultados evidenciaron la activación de procesos de tipo imaginativo y asociativo del neologismo pedalista. Asimismo, se observó que los Modelos Cognitivos Idealizados (MCIs) asociados con el dominio del deporte activan Dominios Cognitivos (DCs) que proceden de experiencias humanas universales.

PALABRAS CLAVES: neologia; semántica cognitiva; Teoría de Espacios Mentales; Teoria de la Integración Conceptual; Modelos Cognitivos Idealizados.

SUMARIO: 1. Introducción: marco teórico. 2. Metodología. 2.1 Metodologia de análisis. 3. Análisis y resultados. 4. Conclusiones.

\section{COGNITIVE-SEMANTICS STUDY OF THE NEOLOGISM PEDAL ISTA IN THE COLOMBIAN SPAN- ISH VARIANT}

ABSTRACT: This study presents a cognitive-semantics analysis of the neologism pedalista, which is formed from one of the most predominant suffixes in the variant of colombian Spanish. Firstly, the neologisms formed by suffixation taken from the digital copies of the newspaper El Tiempo (2014) and systematized by the "Antena $\mathrm{Neo}$ lógica Colombiana” (ANECOL), were identified and classified. Sub sequently, the suffix -ista was established as the greater occurence frequency. Finally, a cognitive-semantics analysis of the neologism pedalista from the Theory of Mental Spaces (Fauconnier, [1985] (1994)), and Conceptual Integration (Fauconnier and Turner, 2001) was conducted. The results evidenced the activation of imaginative and associative processes of the neologism pedalista. Additionally, it was observed that the Idealized Cognitive Models (ICMs) associated with the domain of sports activate Cognitive Domains (CDs) that come from universal human experiences.

KEY WORDS: neology; cognitive semantics; Mental Spaces Theory; Conceptual Integration Theory; Idealized Cognitive Models.

SUMMARY: 1 . Introduction: theoretical framework. 2. Methodology. 3. Analysis and Results. 4. Conclusions.
Óscar Andrés Calvache Dulce Coordinador del Instituto de

Idiomas y docente-investigador del Grupo de Investigación CITERM

(Centro de Investigación

Terminológica)

Universidad Autónoma de Manizales

Antigua Estación del Ferrocarril

Manizales - Caldas - Colombia

E-mail: oscarac@autonoma.edu.co

\section{ÉTUDE SEMANTIQUE-COGNITIVE DU NEOLOGISME PEDALISTA DANS LA VARIANTE DE L'ESPAGNOL COLOMBIEN}

RÉSUMÉ: Cette étude présente une analyse sémantique-cognitive du néologisme pedalista dont la formation provient d'un des suffixes les plus prédominants dans la variante colombienne espagnole. En premier lieu, les néologismes formés par suffixation, systématisés par l'Antena Neológica Colombiana (l'antenne néologique colombienne, ANECOL), des exemplaires électroniques du journal El Tiempo de 2014, ont été identifiés et classés. Par la suite, il a été établi que - ista était le suffixe avec le plus grand nombre d'occurrences. Enfin, une analyse sémantiquecognitive du néologisme pedalista a été réalisée à partir de la Théorie des espaces mentaux (Fauconnier, [1985] (1994)) et de l'intégration conceptuelle (Fauconnier et Turner, 2001). Les résultats ont montré l'activation des processus imaginatifs et associatifs du néologisme pedalista. De même, il a été observé que les modèles cognitifs idéalisés (MCIs) associés au domaine du sport activent des domaines cognitifs (DCs) qui procèdent d'expériences humaines universelles.

MOTS CLÉS: néologie; sémantique cognitive; Théorie des Espaces Mentaux; Théorie de l'intégration Conceptuelle; Modèles cognitifs idéalisés.

SOMMAIRE: 1 . Introduction: cadre théorique. 2. Méthodologie. 3. Analyse et résultats. 4. Conclusions.
Fecha de Recepción Fecha de Revisión Fecha de Aceptación Fecha de Publicación
$04 / 09 / 2018$

$25 / 03 / 2019$

$17 / 05 / 2019$

01/12/2019 DOI: http://dx.doi.org/10.25267/Pragmalinguistica.2019.i27.18 


\section{Estudio semántico-cognitivo del neologismo pedalista en la variante del español de Colombia}

Mercedes SuÁRez de la Torre, Diana lorena Giraldo Ospina \& Óscar Andrés Calvache DULCE

\section{INTRODUCCIÓN: MARCO TEÓRICO}

Las lenguas son cambiantes, dinámicas y flexibles con respecto a las transformaciones generadas en una comunidad de hablantes, en la que usualmente se incorporan nuevas unidades léxicas debido a la necesidad de caracterizar, denominar, definir, resignificar y comunicar. Estas nuevas palabras o unidades léxicas adoptadas por una comunidad lingüística se conocen como neologismos. Según Alcoba (2007) un neologismo es una palabra o frase nueva, parcialmente nueva o formada por una combinación de palabras con una nueva acepción presente en una lengua. Asimismo, Adelstein et al. (2008) señalan que estas nuevas palabras y la resignificación de las ya existentes son evidencia de la capacidad de la lengua para adaptarse a las necesidades de una comunidad. En este sentido, la neología deviene un indicador de la vitalidad de la lengua.

Según lo anterior, autores como Cabré et al. (2002), Fuentes et al. (2008), Domènech y Estopà (2011) y Giraldo (2016) sugieren que las lenguas cuentan con una gran variedad de procesos de creación neológica como parte de la competencia lingüistica de los hablantes, lo que refleja la evolución natural de las lenguas y la sociedad. De igual manera, afirman que los hablantes utilizan, generalmente, patrones y recursos similares que permiten describir las palabras ya existentes en una lengua.

Por su parte, Vallès (2002) considera que los neologismos tienen una dimensión social y otra temporal; es decir, que se pueden diferenciar las palabras nuevas de las ya existentes por medio de la utilización de córpora de referencia recientes. En este sentido, el trabajo de $\mathrm{ANECOL}^{1}$ se realiza con base en la utilización de diferentes córpora de exclusión tales como, el Diccionario de la Real Academia de la Lengua (2014), el Diccionario de Uso del Español de América y España (2003) y el Diccionario de Colombiano Actual (Celis, 2005) ${ }^{2}$. Este trabajo se enmarca dentro de la tipologización de neologismos propuesta por Cabré (2006):

\begin{tabular}{|l|}
\hline Neologismo formal por sufijación (FSUF) \\
\hline Neologismo formal por prefijación (FPRE) \\
\hline Neologismo formal por interferencias entre sufijación y prefijación (FPRSU) \\
\hline
\end{tabular}

\footnotetext{
${ }^{1}$ La Antena Neológica Colombiana (ANECOL) pertenece al Proyecto Antenas Neológicas del Observatorio de Neología del IULA de la Universitat Pompeu Fabra de Barcelona.

${ }^{2}$ Para efectos del trabajo de la Antena Neológica Colombiana (ANECOL), este diccionario se utiliza como corpus de exclusión.
} 


\begin{tabular}{|l|}
\hline Neologismo formal por composición (FCOM) \\
\hline Neologismo formal por composición culta (FCULT) \\
\hline Neologismo formal por lexicalización (FLEX) \\
\hline Neologismo formal por conversión sintáctica (FCONV) \\
\hline Neologismo formal por sintagmación (FSINT) \\
\hline Neologismo formal por siglación (FTSIG) \\
\hline Neologismo formal por acronimia (FTACR) \\
\hline Neologismo formal por abreviación (FTABR) \\
\hline Neologismo formal por variación (FVAR) \\
\hline Neologismo sintáctico (SINT) \\
\hline Neologismo semántico (S) \\
\hline Préstamo M/AM (Préstamo adaptado) \\
\hline
\end{tabular}

Tabla 1: Tipología de neologismos (Cabré, 2006)

Este trabajo se centra, específicamente, en el neologismo pedalista cuya formación se da a partir de uno de los procesos de formación de unidades léxicas más predominante en Colombia, debido a su frecuencia de aparición: la sufijación (Calvache et al., 2011).

Alvar (1993), Monge (1996), Capanaga (2001), Cabré et al. (2002), Santana et al. (2005) y Felíu (2009) coinciden en que la sufijación es uno de los procesos más productivos e importantes de la derivación para la formación de nuevas unidades léxicas en la lengua española. Adicionalmente, Capanaga (2001) sugiere que la sufijación es un proceso de formación de palabras que ofrece una gran vitalidad en la lengua, en cuanto permite alternar un mismo sufijo para múltiples funciones. Es decir, que un mismo sufijo puede tener varios significados dependiendo del uso de las nuevas palabras que forma. Tal es el caso del sufijo -ista en neologismos como chavista que, según su contexto, puede referirse a un seguidor de la doctrina politica de Hugo Chávez y pesista que hace referencia a una persona que practica el deporte de levantamiento de pesas de manera profesional o como aficionado. En estos dos contextos puede observarse que -ista no solamente hace referencia a una filiación política, sino también a un oficio.

\subsection{VALORES SEMÁNTICOS DEL SUFIJO -ISTA}

Según los valores semánticos del sufijo -ista encontramos que éste, según Capanaga (2001), se distingue por su capacidad neológica y el aumento de su frecuencia en los registros a partir de 1989. De igual manera, en los datos registrados por ANECOL, se observa que desde el 2010 hasta el 2014 se presentó un incremento significativo en el uso del sufijo -ista para la creación de nuevas unidades léxicas, tal y como se presenta en la Figura 1. 


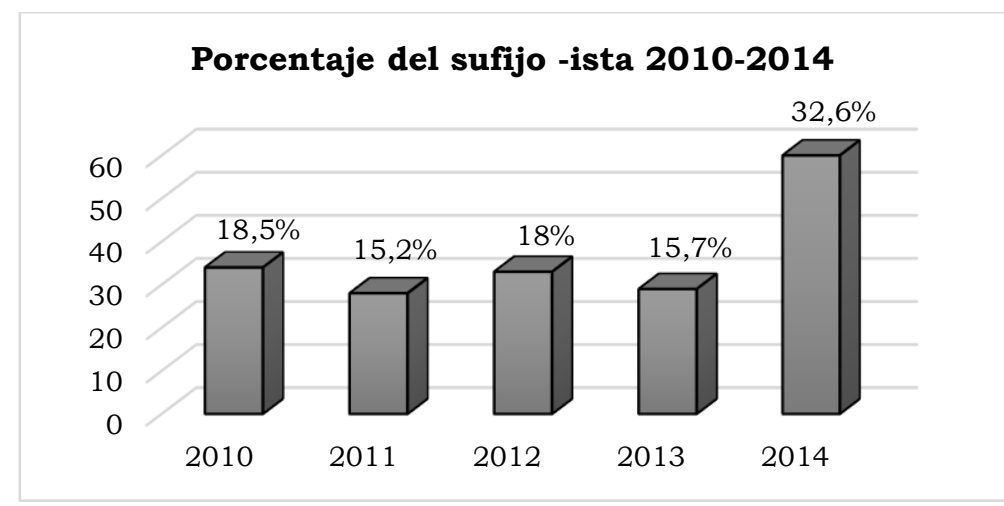

Figura 1: Sufijo -ista años 2010-2014

Autores clásicos como Meyer-Lübke (1890-1906) y Alemany Bolufer (1920) presentan una propuesta en cuanto a los valores semánticos del sufijo -ista. En primer lugar, el sufijo -ista puede referirse a: a) designaciones profesionales, es decir, personas que han recibido una formación académica; b) convicciones políticas, partidarios de las doctrinas filosóficas y de tendencias científicas y políticas; c) descripciones del carácter de una persona, a veces con una valoración negativa, y d) designaciones de participantes o miembros de un grupo, profesión, oficio, hábito u ocupación.

Rainer (1999) coincide con la clasificación anterior en dos aspectos. El primero en referencia a 'partidario de' y, el segundo, respecto a 'las disposiciones presentadas como negativas'. Por su parte, Lang (1992) y Santiago y Bustos (1999) establecen agrupaciones con los siguientes significados para el sufijo -ista: a) miembros representativos de movimientos políticos; b) profesiones; c) ocupaciones artísticas, y d) deportistas. Además de las categorias mencionadas, Capanaga (1999) incluye una nueva acepción en la cual se sugiere otro valor semántico para el sufijo -ista: partidarios de un club deportivo. Por último, Beniers (1996) presenta las funciones semánticas de -ista en las siguientes categorias: a) como agente; b) como poseedor; c) con función de pertinencia; d) como seguidor, y e) con valor adjetival.

Finalmente, tanto Calvache et al. (2019) como Berri y Bohrn (2009), presentan la propuesta de Santiago y Bustos (1999) en la cual señalan que ista tiene por finalidad no solo nominar, sino también adjetivar para formar nuevas unidades léxicas al adherirse a lexemas.

Tal y como se ha descrito en este apartado, el sufijo -ista se ha estudiando desde una perspectiva semántica y a éste se le han otorgado unos determinados valores semánticos independientemente del contexto en los cuales emerge. El presente trabajo contribuye a complementar los estudios mencionados anteriormente, a partir de la descripción de la construcción cognitiva del significado del neologismo pedalista analizado desde las Teorias de los Espacios Mentales y la Integración Conceptual, teorías que proponen Dominios Cognitivos (en adelante DCs) y Modelos Cognitivos Idealizados (en 
adelante MCIs) que se activan en dicha construcción. ${ }^{3}$ Esta complementación se debe a que la semántica cognitiva evidencia el surgimiento de nuevos valores semánticos a partir de la perspectiva constructivista del significado, la cual es dependiente, en gran parte, del o los contextos y, por lo tanto, estos valores no se establecen aislados de su realidad contextual.

\subsection{Perspectiva Semántico-Cognitiva}

\subsubsection{TEORÍA de los Espacios Mentales}

Se ha estimado, desde la perspectiva semántica, que las palabras tienen un significado propio formado por lexemas y afijos; sin embargo, la Teoría de los Espacios Mentales muestra una perspectiva complementaria en cuanto al significado, el cual varía o depende del contexto, los MCIs o los DCs que se activan durante la construcción del mismo.

Calderón (2004) afirma que la Teoría de los Espacios Mentales, así denominada por Fauconnier ([1985] (1994)), propone que las expresiones lingüísticas no contienen significado por sí mismas, sino que permiten al sujeto construir el significado e interpretar el mensaje; es decir, que la interpretación del mensaje depende de los conocimientos que el receptor tenga sobre el DC que se activa por medio de la información explícita proporcionada y que va orientando al lector en la creación de nuevos espacios mentales, en donde se integran la información, tanto implícita como explícita. Fauconnier define los espacios mentales como:

[...] construcciones cognitivas temporales configuradas según las directrices aportadas por las expresiones lingüísticas del discurso, directrices que a su vez activan DCs y MCIs, que por contra son estructuras cognitivas relativamente permanentes y estables. (Fauconnier, 1994: 16)

Por su parte, Pascual (2012) afirma que para Fauconnier ([1985] (1994)) los espacios mentales son dominios de cognición ocultos detrás del escenario y estos dominios se constituyen como conceptos parciales de realidades posibles configurados a partir del discurso.

Según Fauconnier (1994) los DCs y los MCIs contribuyen a la configuración de los espacios mentales, pero no constituyen el espacio mental en sí; es decir que, los espacios mentales son estructuras cognitivas no permanentes que emergen a partir de la información contextual y la información previa presente en los DCs y los MCIs. Uno de los aportes más significativos de Faucconier (1994) consiste en plantear que el discurso lingüístico genera algunas construcciones cognitivas, pero no en su totalidad, ya que también se configuran a partir de los DCs y los MCIs. Por tanto, si bien el contexto

\footnotetext{
${ }^{3}$ Este neologismo fue seleccionado para ilustrar este proceso de construcción de significado. De otra parte, cabe señalar que este trabajo no tiene intención de establecer clasificaciones como las descritas desde la perspectiva semántica, debido a las finalidades que persigue la semántica cognitiva.
} 
guía al lector en la construcción de espacios mentales, los DCs y los MCIs también cumplen un papel fundamental en la construcción de los mismos y del significado.

Los espacios mentales son intermediarios entre la expresión lingüística y la representación mental que el sujeto crea a partir de estos, lo que permite comprender determinada situación. Sin embargo, esto no garantiza que la estructura del espacio mental creado corresponda a la realidad que se pretende mostrar o expresar. Por ello, según Fauconnier (1997), es importante resaltar que la capacidad creativa del receptor y el emisor del mensaje es primordial en el procesamiento de la información para lograr una comunicación efectiva. También, los factores contextuales presentes en el acto comunicativo le permiten al sujeto comprender su propia realidad y la que lo rodea.

En sintesis, las construcciones de espacios mentales están mediadas por los conocimientos previos que los individuos tienen con base en sus experiencias y en su propia realidad y no necesariamente por las estructuras lingüisticas previamente determinadas, las cuales son aspectos superficiales que sólo muestran "la punta del iceberg" del texto o el discurso (Fauconnier [1985] (1994)). Esto es, detrás de un enunciado se configuran diferentes procesos mentales que se nutren de elementos lingüísticos, extralingüísticos y contextuales que permiten interpretar el significado y, por tanto, lograr la finalidad comunicativa.

\subsubsection{TEORÍA DE LA INTEGRACIÓN CONCEPTUAL}

La Teoria de los Espacios Mentales evolucionaria posteriormente a lo que se denominaría la Teoría de la Integración Conceptual o Blending (Fauconnier y Turner, 2001; Turner y Fauconnier, 1998; Grady et al., 1999; Coulson y Matlock, 2001). Esta teoría, en la que convergen la Teoría de los Espacios Mentales y de la Metáfora Conceptual, propone la existencia de redes de espacios mentales dependientes entre sí que se integran y se configuran de la siguiente manera: los dos primeros espacios que se presentan son los espacios de entrada, los cuales comparten estructuras y características comunes que se proyectan a un tercer espacio denominado espacio genérico. El cuarto espacio corresponde a un espacio de integración en el que convergen la información de los espacios de entrada, por medio del espacio genérico (Ver Figura 2). 


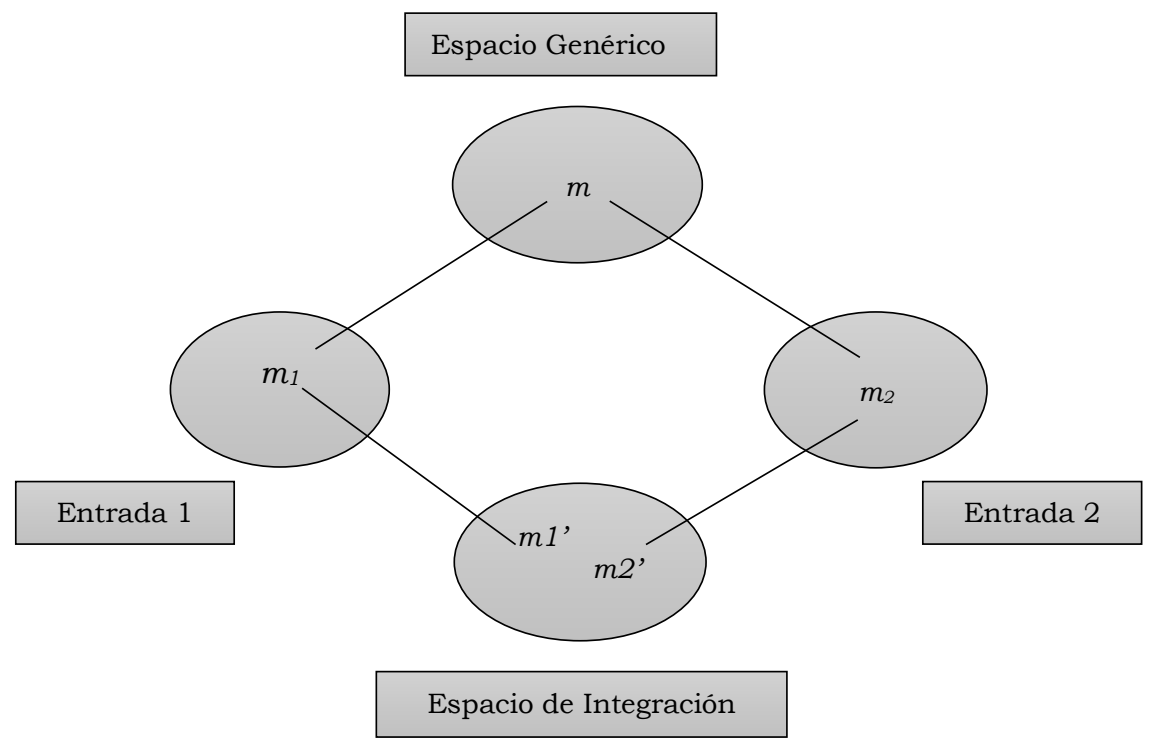

Figura 2: Estructura de la integración conceptual

La integración conceptual, en palabras de Pascual:

[...] supone una comprensión a escala humana, es decir, una reducción o ampliación que convierte aquello de lo que se trata a dimensiones computables. Dicha comprensión surge de la proyección selectiva de elementos, propiedades, procesos y/o relaciones en los espacios de entrada. Pascual (2012:155)

En conclusión y según Pascual (2012), la Teoría de la Integración Conceptual evidencia una habilidad imaginativa por parte del sujeto, que se refleja en el uso creativo del lenguaje y en otras formas de comunicación. Es decir, se toman como base los elementos lingüísticos de un enunciado; sin embargo, no se quedan en ese plano, sino que trascienden a procesos imaginativos y asociativos que permiten comprender a cabalidad lo que se quiere comunicar.

\section{Metodología}

La metodología de este trabajo se desarrolló en cinco etapas. En la primera, se tomaron como punto de partida 30 ejemplares electrónicos del periódico El Tiempo de circulación nacional colombiana del año 2014. En la segunda etapa, a partir de la identificación de los neologismos extraídos de la herramienta semiautomática $\mathrm{BUSCANEO}^{4}$, se realizó el procesamiento $\mathrm{y}$

\footnotetext{
${ }^{4}$ BUSCANEO es un extractor de neologismos que trabaja con textos de internet. Opera con un gestor de diccionarios que permite trabajar contextos de varias lenguas. El programa hace parte de la plataforma OBNEO (Observatorio de Neologia).
} 
validación de los neologismos encontrados. Una vez se llevó a cabo el proceso de validación, se encontró que la sufijación es el proceso de formación de neologismos con mayor número de ocurrencias (30,3\%), seguido por prefijación $(24,9 \%)$ y composición culta $(20,2 \%)$ (Ver Figura 3$)$.

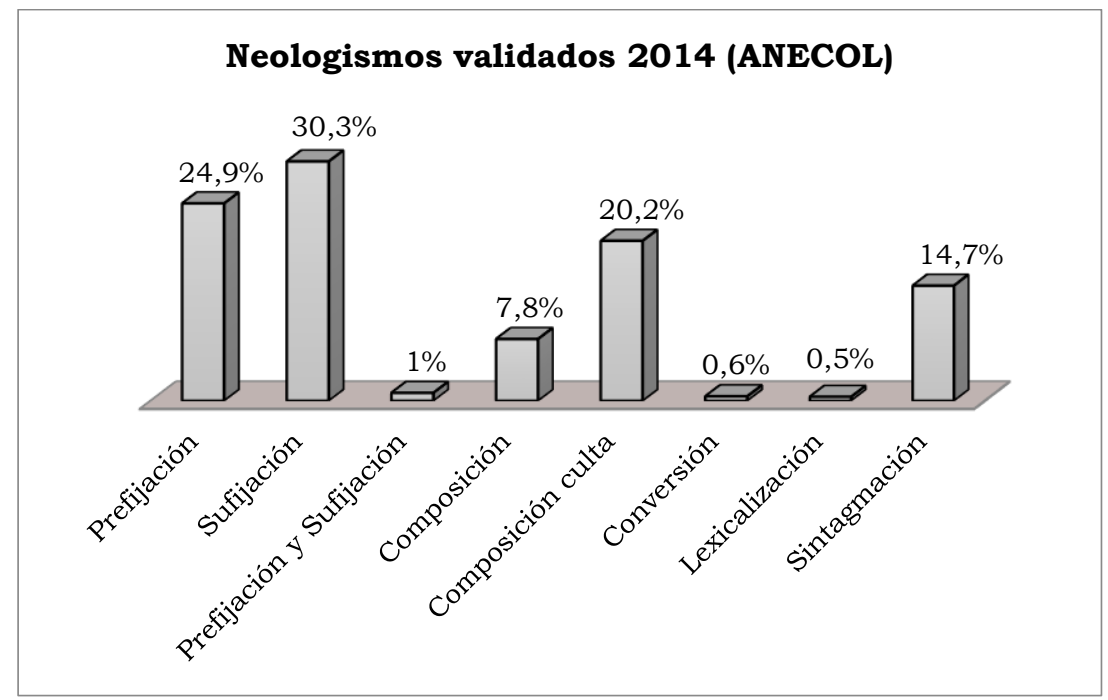

Figura 3: Neologismos validados 2014 (ANECOL). Vaciado semiautomático

En la tercera etapa, tras la identificación de este proceso de formación, se evidenció que -ista fue el sufijo más predominante con 108 ocurrencias $(29,5 \%)$, seguido por -ero con $70(19,1 \%)$ e -ismo con 50 ocurrencias $(13,7 \%)$. (Ver Figura 4).

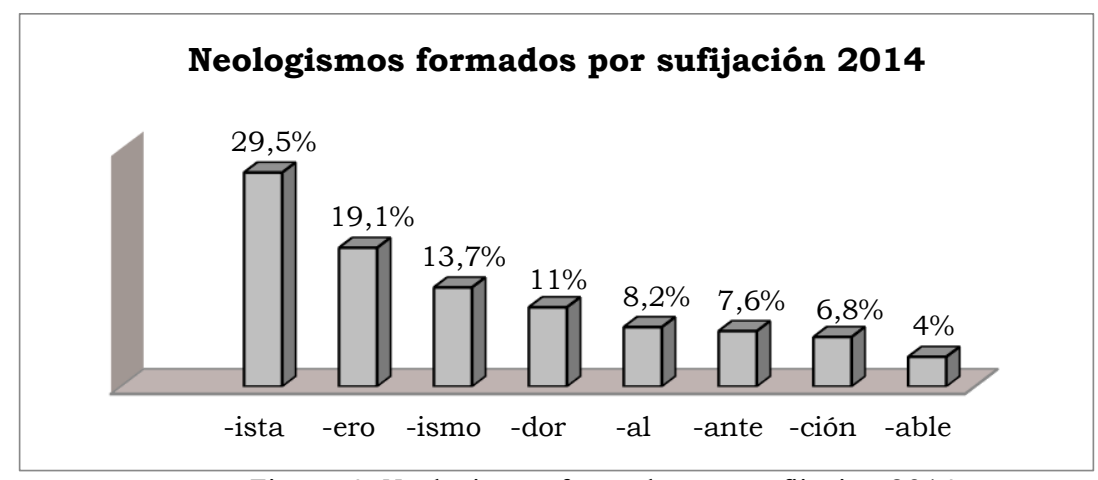

Figura 4: Neologismos formados por sufijación 2014.

La cuarta etapa consistió en la identificación de los diversos neologismos formados por el sufijo -ista. Posteriormente, se establecieron 8 categorias temáticas con base en los contextos en los que se encontró cada neologismo 
y se contabilizó el número de entradas 5 , tomando como punto de partida las 108 ocurrencias de los neologismos que surgen a partir de este sufijo (Ver Tabla 2).

\begin{tabular}{|c|c|c|c|}
\hline Categoria & Neologismos & $\begin{array}{c}\text { Número de } \\
\text { neologismos }\end{array}$ & $\begin{array}{c}\text { Número de } \\
\text { entradas }\end{array}$ \\
\hline POLÍTICA & $\begin{array}{l}\text { chavista (7), clientelista (6), contabi- } \\
\text { lista (1), gavirista (1), guerrerista (2), } \\
\text { injerista (1), hactivista (1), jotajotista } \\
\text { (1), petrista (2), reeleccionista (3), } \\
\text { santista (15), soberanista (2), uribista } \\
\text { (18), yihadista (14) }\end{array}$ & 14 & 74 \\
\hline DEPORTES & $\begin{array}{l}\text { basquetbolista (3), bicicrosista (3), } \\
\text { inicialista (3), marotonista (2), mila- } \\
\text { nista (1), pedalista ( } 7 \text { ) }\end{array}$ & 6 & 19 \\
\hline SOCIEDAD & $\begin{array}{l}\text { estridentista (1), exitista (1), extensio- } \\
\text { nista (1), forista (1), reduccionista (1) }\end{array}$ & 5 & 5 \\
\hline MODA & fashionista (3), patronista (1) & 2 & 4 \\
\hline TECNOLOGÍA & radialista $(1)$ & 1 & 1 \\
\hline BIOLOGÍA & biologista (1), zootecnista (2) & 2 & 3 \\
\hline LITERATURA & reseñista (1) & 1 & 1 \\
\hline EDUCACIÓN & tallerista (1) & 1 & 1 \\
\hline \multicolumn{2}{|r|}{ Número total de neologismos } & 32 & \\
\hline \multicolumn{2}{|r|}{ Número total de entradas } & & 108 \\
\hline
\end{tabular}

Tabla 2: Neologismos formados por el sufijo -ista

Una vez analizadas las entradas, se encontró que la categoría Política, al igual que la categoría Deportes, presentaron el mayor número de ocurrencias. Para efectos de este trabajo, la categoría de análisis seleccionada fue Deportes. De una parte por ser un valor semántico que adiciona Capanaga (1999) a las demás clasificaciones y, de otra parte, por los intereses específicos de la Antena Neológica Colombiana. ${ }^{6}$

Finalmente, los datos evidenciaron que dentro de la categoría Deportes, el neologismo pedalista fue el que presentó el mayor número de entradas (7). Por tanto, dicho neologismo se constituyó como unidad de análisis.

Con base en lo anterior y previo al análisis semántico-cognitivo del neologismo en cuestión, se realizó una búsqueda etimológica y semántica del mismo. Por una parte, el neologismo pedalista se compone de la palabra proveniente del latín pedālis que quiere decir "del pie", según el Diccionario

\footnotetext{
${ }^{5}$ Se entiende por entradas las veces en las cuales aparecen los neologismos en diferentes contextos.

${ }^{6}$ En estudios previos realizados por ANECOL se han trabajado diferentes neologismos referidos a la política (Calvache et al., 2011 y Calvache et al., 2019).
} 
de la Lengua Española (2014), y el sufijo -ista que, según una de sus acepciones, indica profesión u oficio. Por otra parte, se evidenció que el elemento pedal constituye un mecanismo fundamental utilizado en otros artefactos tales como, la guitarra eléctrica, la batería como instrumento musical, la máquina de coser, el carro, la unidad odontológica, entre otros; no obstante, quienes hacen uso de estos pedales para el funcionamiento de estos artefactos no son llamados pedalistas.

Los contextos de uso de este neologismo solo se relacionan con el ciclismo, haciendo referencia a la persona que utiliza el pedal para el movimiento de la bicicleta. Al igual que en el ciclismo, la relación entre pedalpedalista y rueda-ciclista muestra que se toma una parte fundamental de la bicicleta más el sufijo -ista para representar la persona que la utiliza.

A continuación se ilustran los contextos del neologismo pedalista utilizados para el análisis semántico-cognitivo (Ver Tabla 3):

\begin{tabular}{|c|l|}
\hline & \multicolumn{1}{|c|}{ Contextos del neologismo } \\
\hline $\begin{array}{c}\text { Contexto 1 } \\
\text { (C1) }\end{array}$ & $\begin{array}{l}\text { El pedalista colombiano Álex Cano será el líder del equipo Orgullo Antio- } \\
\text { queño, que fue presentado este jueves en Medellín, con miras a la tempo- } \\
\text { rada del 2014. }\end{array}$ \\
\hline $\begin{array}{c}\text { Contexto 2 } \\
\text { (C2) }\end{array}$ & $\begin{array}{l}\text { En Rotterdam (Holanda), en el marco del Mundial de BMX Supercross, Ma- } \\
\text { riana se adjudicó la medalla de bronce en la misma competencia, que en } \\
\text { aquella ocasión quedó en manos de la pedalista local Laura Smulders, } \\
\text { quien ocupó el séptimo lugar. }\end{array}$ \\
\hline
\end{tabular}

Tabla 3: Contextos del neologismo pedalista.

\subsection{METOdología de ANÁLISIS}

La metodologia de análisis que se presenta en este trabajo se basa en una propuesta realizada por Calderón (2004) en la que se tienen en cuenta las habilidades cognitivas del lector competente para interpretar el discurso y que permite evidenciar los procesos imaginativos y asociativos implicados en la construcción del significado durante la lectura, en este caso, de los dos contextos en los que aparece el neologismo pedalista. Esta propuesta se basa en un método integrador que contempla varias fases, con el fin de realizar un análisis semántico-cognitivo que comprende la Teoría de la Integración Conceptual. Las fases que hemos tomado y adaptado de esta metodología son: la fase de aproximación y la fase de construcción del significado.

Dentro de la fase de aproximación, Calderón (2004) propuso un acercamiento a la información específica y a las estructuras cognitivas que forman parte del proceso de comprensión. En primer lugar, esta fase abarca los DCs y los MCIs que se van activando a lo largo de los contextos, así como la relación entre estos. En segundo lugar, se propone un acercamiento a la información experiencial que se activa por medio de expresiones físicas de tipo sensorial y orientacional.

En la fase de construcción del significado se contemplan los espacios mentales que se van activando a lo largo de los contextos, así como las relaciones de dependencia establecidas entre ellas y a un cambio de marco, si 
es necesario. Posteriormente, se identificaron los espacios de entrada (EE) en cada uno de los contextos, el espacio genérico (EG) y el espacio de integración (EI) en el que, a través del espacio genérico, se acomodan informaciones específicas provenientes de los $\mathrm{EE}$.

\section{ANÁLISIS Y RESULTADOS}

\subsection{FASE DE APROXIMACIÓN}

\subsubsection{Dominios Cognitivos (DCs) y Modelos Cognitivos Idealizados (MCIs)}

La Figura 5 presenta los MCIs, sus dimensiones y los DCs que se activan por medio de los dos contextos previamente mencionados.

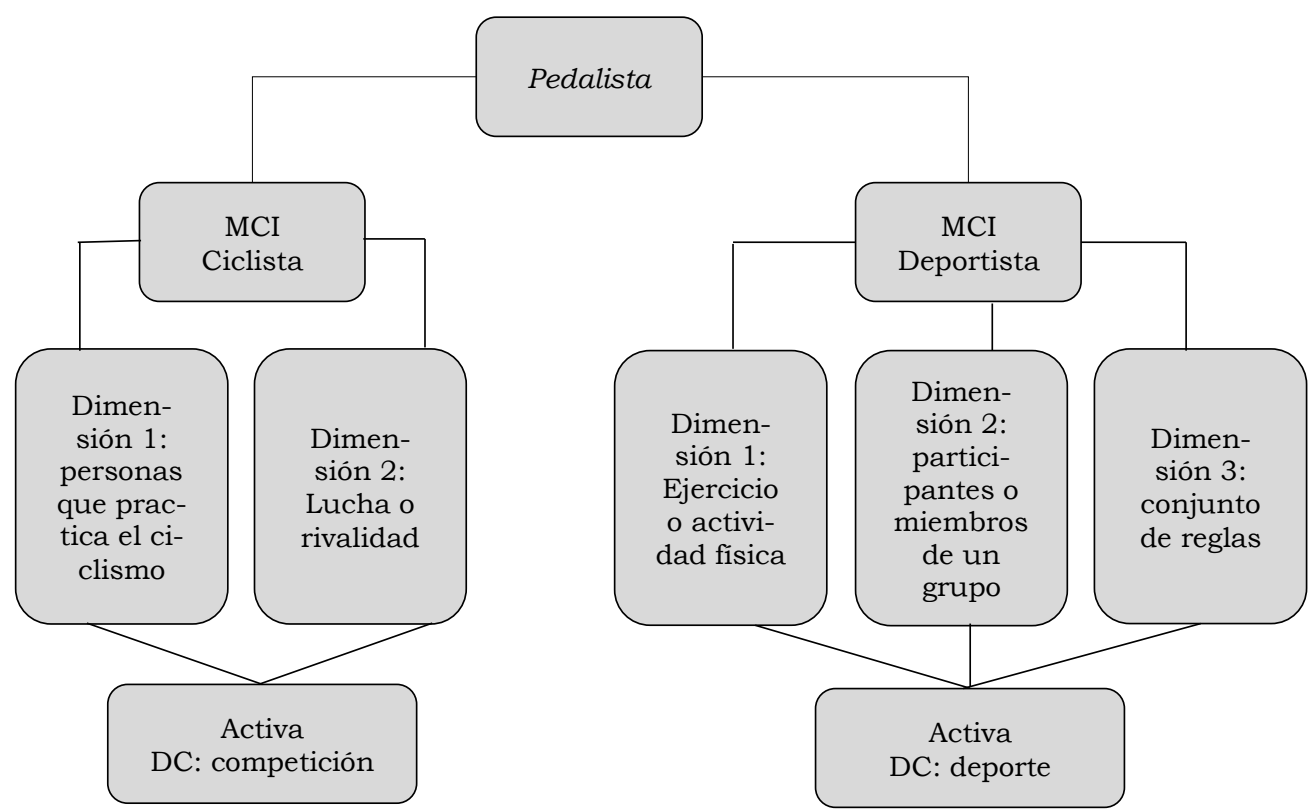

Figura 5: Modelos cognitivos idealizados, dimensiones y dominios cognitivos de pedalista

Tal y como se presenta en la Figura 5, pedalista activa en nuestra mente DCs relacionados con el deporte, más concretamente con la relación entre el deporte y la competición. Pedalista se presenta de manera prototípica como un ciclista o persona que practica el ciclismo.

La dimensión persona que practica el ciclismo perteneciente al MCI ciclista, se activa en cada uno de los contextos, el cual se proyecta y se mantiene a lo largo de ambos textos. Este hecho se observa con la inclusión de elementos como líder de equipo, en el contexto 1 (C1) y mundial de BMX Supercross, en el contexto 2 (C2) (ver Tabla 4). 


\begin{tabular}{|c|l|}
\hline & \multicolumn{1}{c|}{ Dimensión 1: persona que practica el ciclismo } \\
\hline $\mathbf{C 1}$ & $\begin{array}{l}\text { El pedalista colombiano Álex Cano será el líder del equipo Orgullo Antio- } \\
\text { queño, que fue presentado este jueves en Medellín, con miras a la tempo- } \\
\text { rada del 2014. }\end{array}$ \\
\hline C2 & $\begin{array}{l}\text { En Rotterdam (Holanda), en el marco del Mundial de BMX Supercross, Ma- } \\
\text { riana se adjudicó la medalla de bronce en la misma competencia, que en } \\
\text { aquella ocasión quedó en manos de la pedalista local Laura Smulders, quien } \\
\text { ocupó el séptimo lugar. }\end{array}$ \\
\hline
\end{tabular}

Tabla 4: MCI ciclista. Dimensión 1: persona que practica el ciclismo.

Otra dimensión del MCI ciclista (lucha o rivalidad entre quienes se disputan una misma cosa o la pretenden) se mantiene activado; aunque dicha rivalidad se moviliza de forma diferente en los dos contextos (ver Tabla 5): en C1 se manifiesta de manera colectiva, a través de la inclusión del elemento equipo; mientras que en $\mathrm{C} 2$, esta rivalidad se manifiesta de manera individual, es decir, entre cada uno de los competidores, a partir de la inclusión de sus nombres propios: Mariana y Laura Smulders.

\begin{tabular}{|c|l|}
\hline & \multicolumn{1}{c|}{\begin{tabular}{c}
\multicolumn{1}{c|}{ MCI: Ciclista } \\
Dimensión 2: lucha o rivalidad
\end{tabular}} \\
\hline $\mathbf{C 1}$ & $\begin{array}{l}\text { El pedalista colombiano Álex Cano será el líder del equipo Orgullo Antio- } \\
\text { queño, que fue presentado este jueves en Medellín, con miras a la tempo- } \\
\text { rada del 2014. }\end{array}$ \\
\hline $\mathbf{C 2}$ & $\begin{array}{l}\text { En Rotterdam (Holanda), en el marco del Mundial de BMX Supercross, } M a- \\
\text { riana se adjudicó la medalla de bronce en la misma competencia, que en } \\
\text { aquella ocasión quedó en manos de la pedalista local Laura Smulders, quien } \\
\text { ocupó el séptimo lugar. }\end{array}$ \\
\hline
\end{tabular}

Tabla 5: MCI ciclista. Dimensión 2: lucha o rivalidad.

Esta construcción de significado, en su dimensión de lucha o rivalidad, activa un DC relacionado con la competición. Los estímulos lingüisticos que activan la sensación de competencia se manifiestan a través de expresiones tales como: medalla de bronce, misma competencia, ocupó el séptimo lugar.

Otro MCI es el que se activa por la referencia explícita que se hace de los deportistas Mariana, Laura Smulders y Alex Cano (ver Tabla 6).

\begin{tabular}{|c|l|}
\hline & \multicolumn{1}{c|}{ MCI: Deportista } \\
\hline $\mathbf{C 1}$ & $\begin{array}{l}\text { El pedalista colombiano Álex Cano será el líder del equipo Orgullo Antio- } \\
\text { queño, que fue presentado este jueves en Medellín, con miras a la tempo- } \\
\text { rada del 2014. }\end{array}$ \\
\hline $\mathbf{C 2}$ & $\begin{array}{l}\text { En Rotterdam (Holanda), en el marco del Mundial de BMX Supercross, Ma- } \\
\text { riana se adjudicó la medalla de bronce en la misma competencia, que en } \\
\text { aquella ocasión quedó en manos de la pedalista local Laura Smulders, quien } \\
\text { ocupó el séptimo lugar. }\end{array}$ \\
\hline
\end{tabular}

Tabla 6: MCI deportista

En este caso, el MCI deportista conduce a las siguientes dimensiones: 
- Una primera dimensión relacionada con ejercicio o actividad, generalmente, fisica.

- Una segunda dimensión que hace referencia a quienes practican dicha actividad fisica: los participantes o miembros, generalmente, de un equipo.

- Y una última dimensión relacionada con un conjunto de reglas que deben cumplir quienes participan en dicha actividad.

Todas estas dimensiones en conjunto conducen a la conformación del DC deporte.

\subsubsection{INFORMACIÓN EXPERIENCIAL}

En Calderón (2004) se menciona que la Lingüística Cognitiva asume que gran parte de la conceptualización humana nace de la base experiencial del individuo, por lo cual, la transmisión de información conceptual es más efectiva si se da por medio de la expresión de experiencias físicas, tales como las orientacionales y las sensoriales (ver Tabla 7).

La primera experiencia transmitida a través de los contextos en los que aparece el neologismo pedalista es de tipo sensorial y viene condicionada por la dimensión de ciclista como persona que disputa una misma cosa o la pretende. A partir de este modelo se genera un esquema de imagen de competencia que resulta en la dicotomía sensorial GANADOR - PERDEDOR.

Dichas experiencias sensoriales se recrean a través de los siguientes estímulos lingüísticos:

En C1 es evidente que existe un líder de equipo, lo cual hace referencia a la persona que ocupa el primer lugar en una clasificación o competencia. Igualmente, en C2 la referencia a la participante "Mariana, que se adjudicó la medalla de bronce" da lugar a la siguiente interpretación: esta participante ocupó un tercer lugar en el pódium, lo cual indica que esta competidora está a un mejor nivel que Laura Smulders. En ambos contextos se evidencia una experiencia sensorial de ganador. Las sensaciones, por lo tanto, están relacionadas con imágenes de triunfo, victoria, alegría.

Por el contrario, en C2 la referencia a la pedalista "Laura Smulders quien ocupó el séptimo lugar" evidencia una experiencia sensorial de perdedor. Las sensaciones, en este caso, están relacionadas con imágenes de derrota, tristeza, frustración.

De igual manera, estas sensaciones de logro se enfatizan también a través de una dicotomía orientacional ARRIBA-ABAJO, "esquema de imagen que a menudo se adapta a la expresión de dominio de un ser sobre otro" (Calderón, 2004:152). En el caso del C1, se muestra un pedalista que se encuentra a un nivel superior al ser considerado lider del equipo. Por tanto, Alex Cano representa, en esa dicotomía orientacional, la superioridad, mientras que los integrantes del equipo Antioqueño "Orgullo Paisa" corresponden a un nivel inferior. Asimismo, en el $\mathrm{C} 2$, se presenta la misma situación con la relación Arriba (Mariana) y Abajo (Laura Smulders). 


\begin{tabular}{|c|l|}
\hline & \multicolumn{1}{c|}{$\begin{array}{c}\text { Dicotomia sensorial y orientacional: Ganador-Perde- } \\
\text { dor/Arriba-Abajo }\end{array}$} \\
\hline $\mathbf{C 1}$ & $\begin{array}{l}\text { El pedalista colombiano Álex Cano será el líder del equipo_Orgullo An- } \\
\text { tioqueño, que fue presentado este jueves en Medellin, con miras a la } \\
\text { temporada del 2014. }\end{array}$ \\
\hline $\mathbf{C 2}$ & $\begin{array}{l}\text { En Rotterdam (Holanda), en el marco del Mundial de BMX Supercross, } \\
\text { Mariana se adjudicó la medalla de bronce en la misma competencia, que } \\
\text { en aquella ocasión quedó en manos de la pedalista local Laura Smul- } \\
\text { ders, quien ocupó el séptimo lugar. }\end{array}$ \\
\hline
\end{tabular}

Tabla 7: Dicotomía sensorial y orientacional: Ganador-perdedor/arriba-abajo

\title{
3.2. Construcción DEL Significado
}

\subsubsection{Espacios Mentales y Cambio de marco}

En los procesos de construcción de significado, los sujetos generan sus propios espacios mentales con base en la información lingüística asociada a sus propias experiencias. Sin embargo, estos espacios mentales son temporales y pueden generar un cambio de significado dependiendo de la información contextual. Calderón afirma:

\begin{abstract}
La información lingüística que recibimos va guiando al lector competente en la construcción de significado, de manera que la lengua parece constituirse como transmisora del mismo. Pero toda esta información semántica específica, creada en la mente del lector a través de la evocación de dominios cognitivos y modelos cognitivos idealizados (en los que se incluyen las metáforas básicas) no presenta una disposición caótica, sino que se organiza en estructuras mentales creadas ad hoc y que hemos denominado espacios mentales. isiepi:(Calderón, 2004:163)
\end{abstract}

Tal y como se observa en la Figura 6, pedalista es el primer espacio mental (E1) creado a partir del contexto. Siguiendo el modelo cognitivo de pedalista como ciclista, este se completa con el elemento específico: deportista Alex Cano (C1). En este mismo contexto se abre un segundo espacio correspondiente al primero (E1.1) en el que el valor que predomina es el de pedalista como persona que practica el ciclismo a través de la expresión líder del equipo.

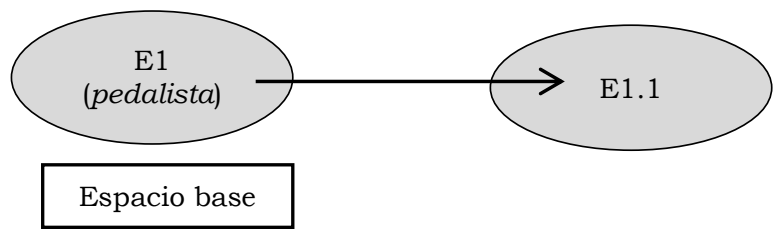

Figura 6: Configuración del espacio mental E1 y E1.1 respecto al contexto $1(\mathrm{C} 1)$

Con base en el último segmento del $\mathrm{C} 1$, "con miras a la temporada del 2014", volvemos al E1 o espacio base, que sigue configurándose a partir de 
otros elementos específicos: "2014", el cual permite la creación de un nuevo espacio: tiempo o temporada (E1.2), como se muestra en la Figura 7.

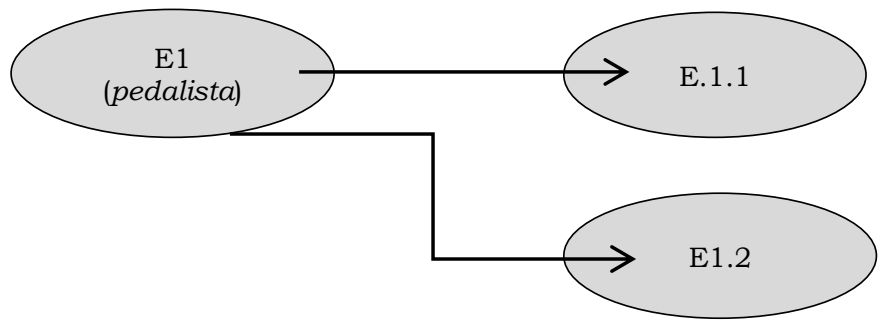

Figura 7: Configuración del espacio mental E1 y E1.2 respecto al contexto $1(\mathrm{C} 1)$

El C2, aunque hace referencia al mismo neologismo pedalista, conduce a un cambio de marco, debido a que se presenta un cambio en la escena. Dicha escena se modifica y amplía porque el lector en este contexto no sólo construye un significado del neologismo desde una perspectiva colectiva (equipo), sino también desde una perspectiva individual (nombres de deportistas). Esta modificación introduce "un cambio en la estructura genérica de los espacios mentales." (Calderón, 2004:13)

El nuevo espacio mental (E2) se configura (ver Figura 8) desde dicha perspectiva individual, en el cual cada deportista es protagonista de la competencia. De esta perspectiva individual (E2) dependen otros espacios mentales representados conceptualmente por: el Mundial BMX Supercross (E2.1), la rivalidad que se evidencia a partir de la adjudicación de medallas (E2.2) y la referencia al lugar ocupado por quien no gana la competencia (E2.2.a).

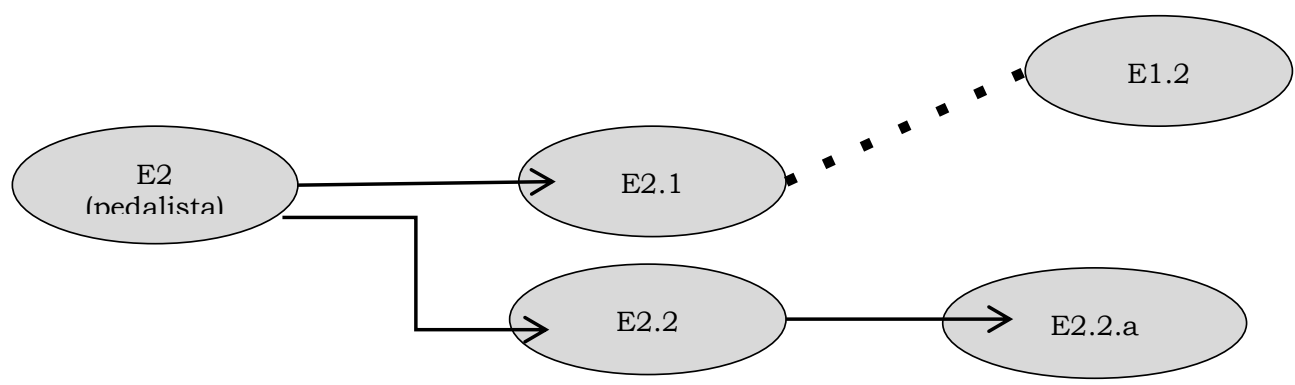

Figura 8: Configuración del espacio mental E2 respecto al contexto 2 (C2)

La Figura 9 representa grosso modo la trayectoria mental del individuo hasta completar la lectura de los dos contextos en los cuales aparece el neologismo pedalista. Aunque el cambio de marco introduce este nuevo espacio mental, cabe resaltar que existe una equivalencia con los espacios mentales 
anteriores, debido a que ambos escenarios se dan en un espacio y tiempo determinados. En C1, espacio y tiempo están representados por los vocablos "Medellin" y "temporada 2014", mientras que en C2 se representan a partir de "Rotterdam (Holanda)" y la celebración de dicho mundial con una periodicidad anual. A pesar de que ambos contextos hacen referencia al neologismo pedalista, en cada uno de ellos se crea una representación mental diferente mediada por los otros elementos que aparecen en los contextos, la experiencia, la imaginación y la creatividad de los lectores.

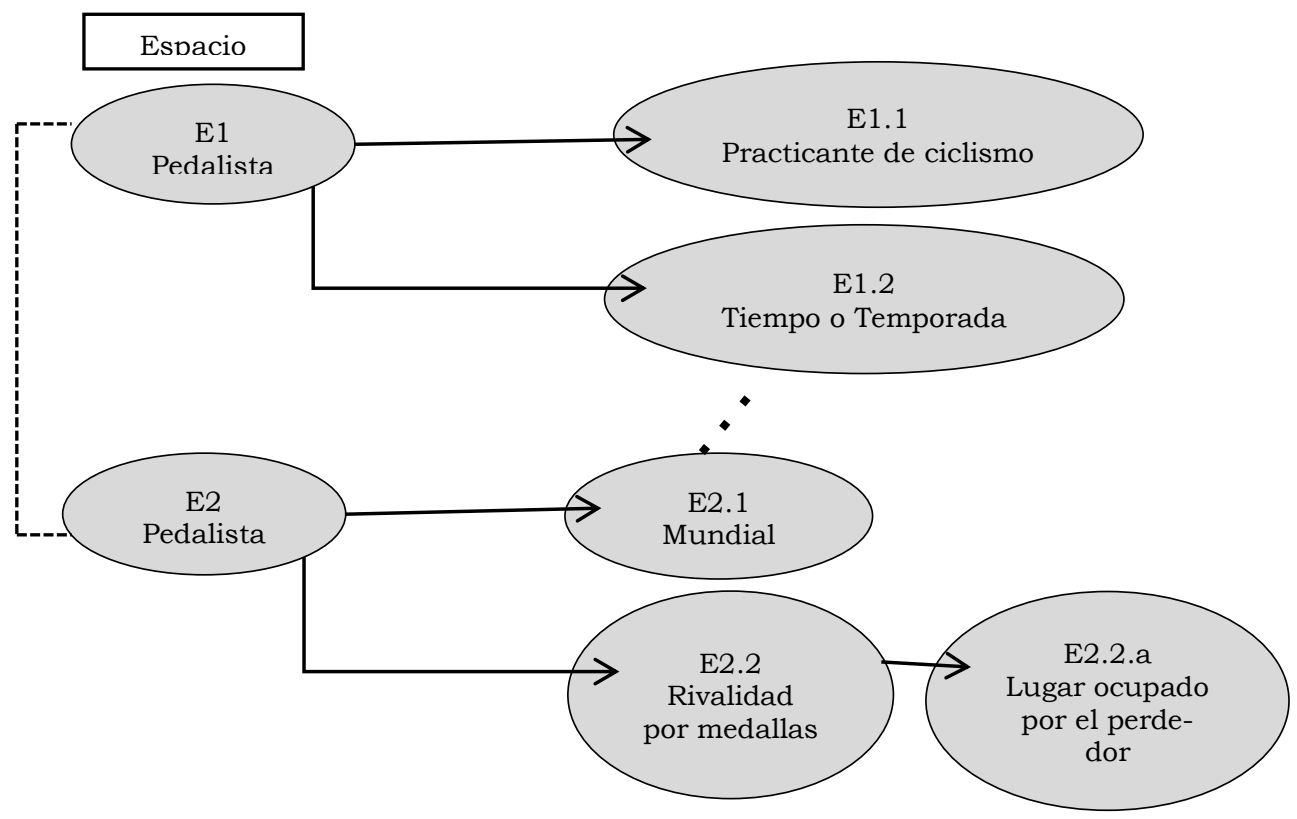

Figura 9: Integración de espacios mentales 1 y 2

\subsubsection{INTEGRACIÓN CONCEPTUAL}

La integración de espacios mentales permite la combinación de los elementos, propiedades, procesos y relaciones, siempre y cuando haya, de alguna manera, similitudes entre estos. Este es el caso de los E1 y E2 que se encuentran conectados mediante la existencia de elementos equivalentes vinculados entre ellos. Para la integración conceptual en la construcción del significado, como se muestra en la Figura 10, se presentan dos espacios de entrada con componentes relacionales, tales como la situación presente en cada contexto $\left(s_{1}\right.$ y $\left.s_{2}\right)$, la competencia $\left(c_{1}\right.$ y $\left.c_{2}\right)$, la duración de la competencia $\left(d_{1}\right.$ y $\left.d_{2}\right)$, la modalidad $\left(m_{1}\right.$ y $\left.m_{2}\right)$, las caracteristicas del trayecto $\left(t_{1}\right.$ y $\left.t_{2}\right)$ y los pedalistas $\left(n_{1}\right.$ y $\left.n_{2}\right)$ ) is ise 


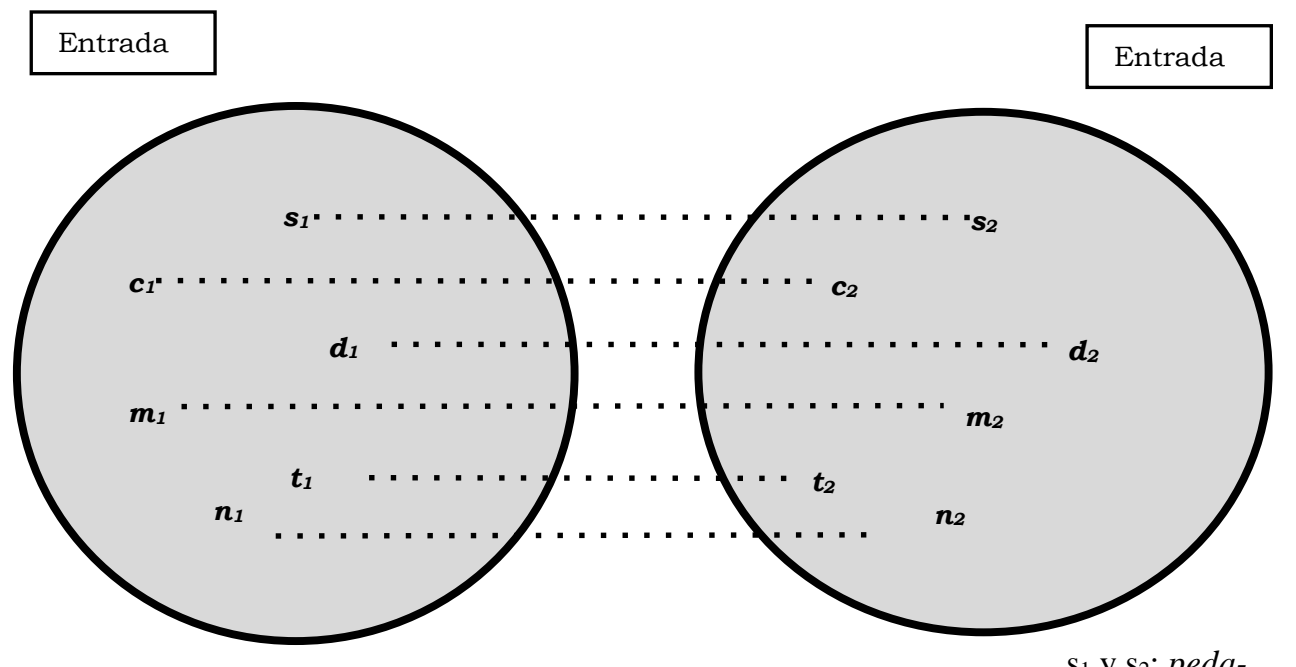

lista en situaciones diferentes

$\mathrm{s}_{1}$ y $\mathrm{s}_{2}: p e d a-$

$\mathrm{c}_{1} \mathrm{y} \mathrm{c}_{2}$ : pedalista en competencias diferentes

$\mathrm{d}_{1} \mathrm{y} \mathrm{d}_{2}$ : duración de la competencia

$\mathrm{m}_{1}$ y $\mathrm{m}_{2}$ : modalidad de la competencia

$\mathrm{t}_{1} \mathrm{y} \mathrm{t}_{2}$ : características de trayectos que recorren

$\mathrm{n}_{1}$ y $\mathrm{n}_{2}$ : pedalista de alto nivel

Figura 10: Integración conceptual espacios de entrada 1 y 2

En primer lugar, para explicar lo anteriormente mencionado, a la luz de los $\mathrm{C} 1$ y C2, podemos evidenciar que en ambos contextos se presentan situaciones diferentes $\left(s_{1}\right.$ y $\left.s_{2}\right)$ para cada una de las competencias, mientras en el C1 Alex Cano se convierte en el líder para competir en la temporada 2014, en el C2 Mariana gana la medalla de bronce en el mundial BMX.

En cuanto a las competencias $\left(c_{1}\right.$ y $\left.c_{2}\right)$ y duración $\left(d_{1}\right.$ y $\left.d_{2}\right)$, en el $\mathrm{C} 1$ no se explicita el tipo de carrera en el cual se va a participar, pero implícitamente se indica que la participación será en diferentes competencias durante el año 2014. Por el contrario, en el C2 se identifica que la participación será en el Mundial BMX Supercross y de manera implícita se entiende que es una competencia corta que dura alrededor de una semana.

En la modalidad de la competencia $\left(m_{1} \mathrm{y} m_{2}\right)$, se evidencia que en el $\mathrm{C} 1$ el trabajo en equipo es fundamental para lograr la meta propuesta; es decir, los integrantes del equipo, que fungen como gregarios, ayudan al líder para que obtenga el primer lugar en las competencias; sin embargo, en el C2 la modalidad es netamente individual y recae en Mariana y Laura la responsabilidad de obtener el logro. 
Por último, en los dos contextos se presentan pedalistas de alto nivel $\left(n_{1}\right.$ y $\left.n_{2}\right)$, que compiten en diferentes trayectos $\left(t_{1} \mathrm{y} t_{2}\right)$, de acuerdo con las caracteristicas de la competencia. En $\mathrm{C} 1$ implicitamente pueden destacarse recorridos de territorios planos, montaña y cronometraje. Por el contrario, en el BMX normalmente hay un circuito entre 350 a 500 metros y la pista se caracteriza por tener un suelo arcilloso compacto para evitar que las ruedas se encajen en el terreno.

En segundo lugar, todos estos elementos (prescindiendo de sus respectivos valores específicos) se encuentran reflejados como esquema de imagen en el espacio genérico y comparten características comunes de los espacios de entrada 1 y 2: la situación (s), la competencia (c), la duración (d), la modalidad $(m)$, las características del trayecto $(t)$ y los pedalistas $(n)$. Es decir, las conexiones y las relaciones existentes en cada uno de los EE están presentes en los contextos y convergen en este espacio genérico, como se muestra en la Figura 11.

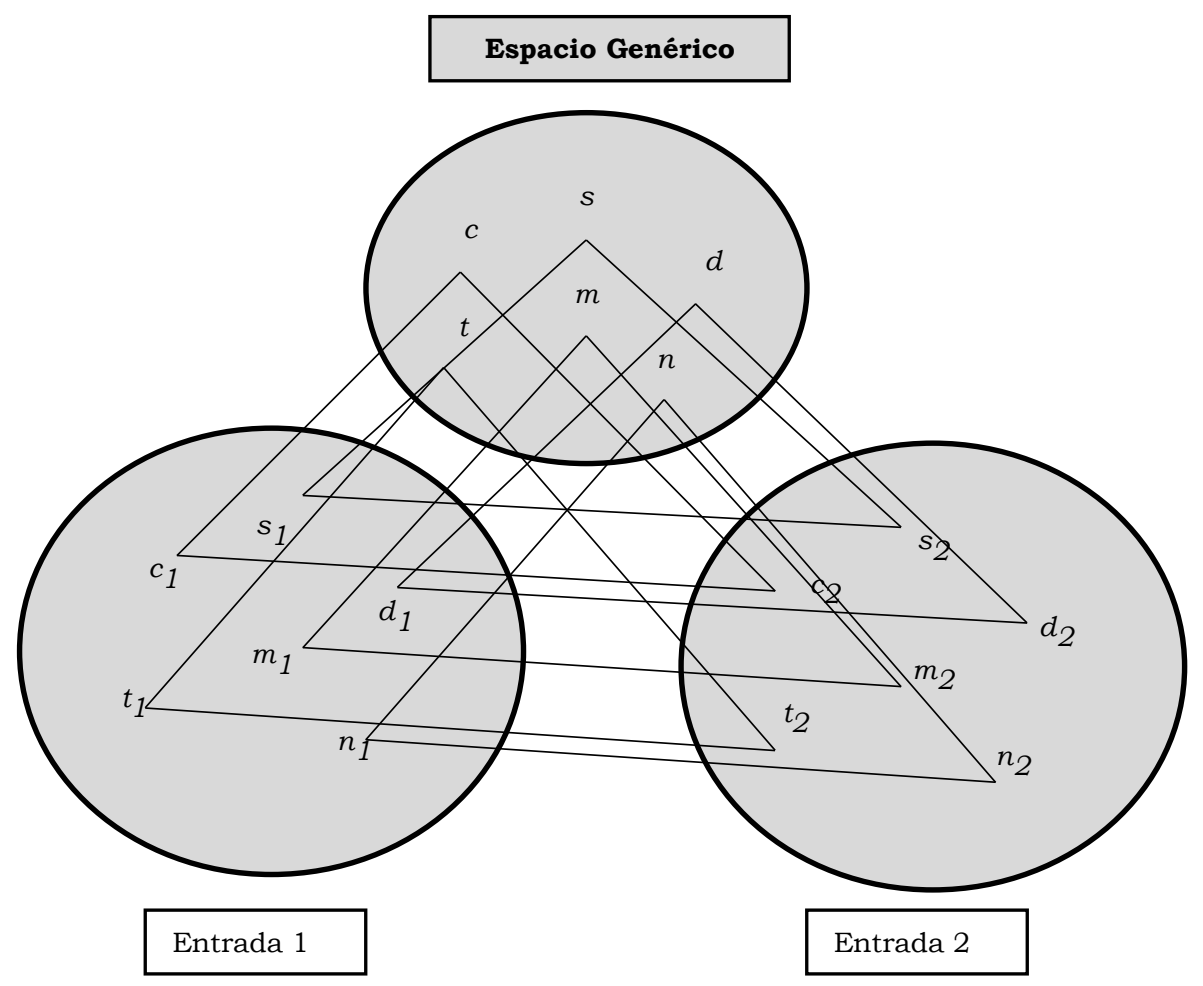

Figura 11: Espacio genérico

En tercer lugar, el esquema de imagen se proyecta sobre el espacio de integración (ver Figura 12), al que se añade posteriormente la información específica procedente de los EE, culminando así la fase de composición: s1', 
$\mathrm{s} 2{ }^{\prime}, \mathrm{c} 1^{\prime}, \mathrm{c} 2$ ', d1', d2', m1', m2', t1', t2', n. Esto indica que a pesar de que se comparten los elementos mencionados anteriormente, existen unas características específicas que los hacen diferenciarse el uno del otro. Por ejemplo, la duración ( $\mathrm{d} 1^{\prime}$ y d2') siempre va a estar presente en el espacio de integración; sin embargo, cada duración depende del tipo de competencia, mientras d1' hace referencia a trayectos en los cuales se deben recorrer largas distancias (horas), en d2' los trayectos se inscriben en competencias de no más de dos minutos. De igual manera, puede evidenciarse en los demás elementos del espacio de integración que todos comparten una característica en común, aunque varía según el contexto.

En el caso de n (pedalista de alto nivel), se observa que los pedalistas en ambos contextos comparten los mismos elementos y características en el espacio de integración. Esto indica que los sujetos hacen una representación mental al leer los contextos y pueden identificar los elementos diferenciales entre uno y otro; sin embargo, el MCI de pedalista cambia en el espacio de integración, teniendo en cuenta las condiciones que se presentan en cada una de las competencias. Mientras en el C1, las características de la competencia están determinadas por la resistencia, el trabajo y las estrategias de equipo, así como la duración y las características del trayecto, en C2 prima la estrategia individual, la fuerza y la rapidez para recorrer el trayecto específico para esta modalidad. Esto quiere decir que se configura un nuevo MCI al integrar los elementos de ambos EE.

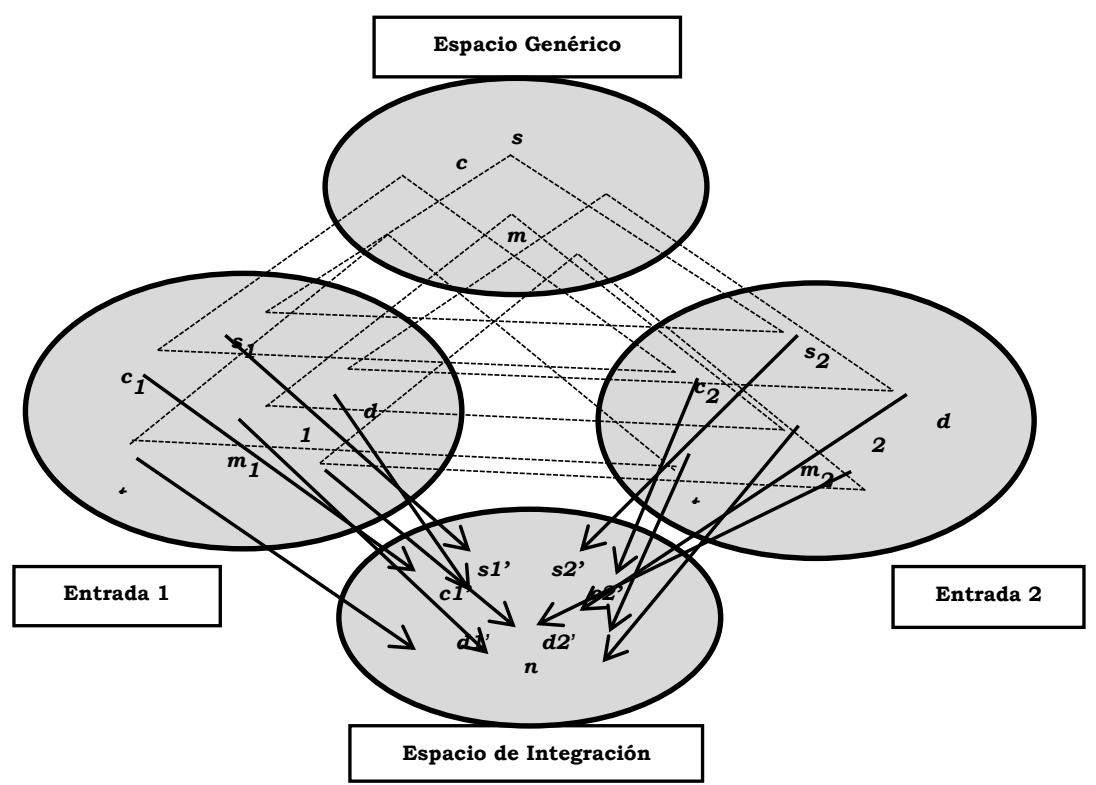

Figura 12: Espacio de integración

En conclusión, en la construcción del significado de pedalista se trasciende a procesos imaginativos y asociativos que permiten comprender lo 
que se quiere comunicar, no sólo a partir de los elementos lingüísticos presentados y las categorizaciones semánticas, sino también a partir de la creación de DCs, MCIs, factores experienciales, imaginación y creatividad del sujeto, mediados por el contexto.

\section{Conclusiones}

El análisis realizado desde la perspectiva semántico-cognitiva permitió evidenciar los siguientes aspectos:

En primer lugar, se concluyó que el análisis semántico-cognitivo, con base en las Teorías de los Espacios Mentales y la Integración Conceptual (Fauconnier y Turner, 2001; Turner y Fauconnier, 1998; Grady et al., 1999; Coulson y Matlock, 2001) permitieron generar construcciones de significado a partir de procesos de carácter imaginativo y asociativo, lo que activa nuevos valores semánticos dependientes de las características del contexto.

En segundo lugar, se observó que aunque se trata del mismo neologismo, éste activa valores semánticos y características particulares en cada uno de los contextos. Es decir, el MCI de pedalista hace referencia a la persona que practica el ciclismo de manera profesional; sin embargo, el significado de este neologismo es contexto-dependiente. Aunque en ambos contextos emergen categorias similares, tales como la temporalidad, el trayecto y la modalidad de competencia, éstas difieren; por ejemplo: mientras en el C1 el trayecto se realiza en terrenos planos, montañosos y de cronometraje, en el C2, se presentan circuitos cortos en terrenos arcillosos. Respecto a la modalidad, en el C1 la competencia es grupal, por el contrario, en el C2 es individual.

En tercer lugar, se evidenció también la generación de otros subvalores semánticos que hacen parte de la categoría deporte ya establecida (Lang (1992); Santiago y Bustos (1999) y Capanaga (1999)). Estos subvalores se activan a partir de características pragmáticas y cognitivas que no se manifiestan de manera explícita, sino que van emergiendo con base en procesos imaginativos, asociativos y experienciales. Tal es el caso de la dicotomía orientacional que activa la perspectiva ganador-perdedor. Cuando el neologismo pedalista evocó MCIs ganadores, se asoció con dimensiones de triunfo, victoria, alegria, celebración; mientras que perdedor evocó dimensiones como derrota, fracaso, tristeza, frustración. En este sentido, se refleja la activación de subvalores semánticos no incorporados en las clasificaciones previas.

Por último, es importante señalar que el análisis presentado constituye un primer ejercicio exploratorio. A futuro, se espera dar evidencia empírica de los procesos cognitivos que se presentan durante la lectura de los contextos en los que aparecen neologismos formados por el sufijo -ista. 


\section{REFERENCIAS}

ADELSTEIN, A., KUGUEL, I. \& RESNIK, G. (2008): 1300 neologismos en la prensa argentina, Argentina: Los Polvorines, Universidad Nacional de General Sarmiento.

ALCOBA RUEDA, S. (2007): Autorización y uso de los neologismos: En R. Sarmiento y F. Vilches. (Eds.), Neologismos y sociedad del conocimiento, Madrid-Barcelona: Fundación Telefónica y Editorial Ariel. S.A, pp. 23-47.

ALEMANY BOLUFER, J. (1920): Tratado de la formación de palabras en la lengua castellana. La derivación y la composición. Estudio de los sufijos y prefijos empleados en una y otra, Madrid: Librería general de Victoriano Suárez.

ALVAR EZQUERRA, M. (1993): La formación de palabras en español, Madrid: Arco Libros.

BENIERS, E. (1992): El sufijo -ismo en el español de México, En: Scripta Philologica in honorem Juan M. Lope Lanch, II. Lingüistica Española e Iberoamericana, México: Universidad Nacional Autónoma de México, pp. 313337.

BERRI, M., Y BOHRN, A. (2009): "La Neología en el Ámbito de la Música: la Formación de Nombres y Adjetivos en -ERO e -ISTA", Debate Terminológico, 5, pp. 522.

CABRÉ I CASTELLVÍ, M. T., BAYÀ FERRERES, M. R., BERNAL GALLÉN, E., FREIXA AYMERICH, J., SOLÉ SOLÉ, E. \& VALLĖS BOTEY, T. (2002): Evaluación de la vitalidad de una lengua a través de la neología: A propósito de la neología espontánea y de la neología planificada: En M.T. Cabré, J. Freixa y E. Solé.
(Eds.), Lexic i Neologia, Barcelona: Observatori de Neologia. Institut Universitari de Lingüística Aplicada, Universitat Pompeu Fabra, pp.159-201.

CABRÉ I CASTELLVÍ, M. T. (2006): "La clasificación de neologismos: una tarea compleja", Alfa, 2, pp. 229-250.

CALDERÓN QUINDÓS, M. T. (2004): Integración Conceptual (Blending) en el discurso y la obra poética de Seamus Heaney. Disertación Doctoral. Universidad de Valladolid, España.

CALVACHE DULCE, Ó., GIRALDO PÉREZ, B., SUÁREZ DE LA TORRE, M. \& SUÁREZ SALAZAR, A. (2011): "El conflicto político armado colombiano como factor determinante para la creación de neologismos en el español de Colombia", Revista Lenguaje, 1, pp. 15-39.

CALVACHE DULCE, Ó., SUÁREZ DE LA TORRE, M. \& SUÁREZ SALAZAR, A. (2019): "Relaciones Semántico-Cognitivas de los Neologismos Formados con los Sufijos -ISMO e -ISTA en la Variante del Español de Colombia”, Revista Signos. Estudios de Lingüistica, 53. № 103. En proceso.

CAPANAGA CABALLERO, P. (1999): Palabras de papel: formaciones neológicas en español, Bologna: CLUEB.

CAPANAGA CABALLERO, P. (2001). Productividad y Registro de las Formas Derivativas y Compositivas. Disponible en: http:/ / cvc.cervantes.es/literatura/aispi/pdf/14/14_101.pdf (fecha de consulta: $01 / 02 / 2018)$

CELIS ALBÁN, F. (2005): Diccionario de Colombiano Actual, Bogotá: Círculo de Lectores. S.A. 
COULSON, S. Y MATLOCK, T. (2001): "Metaphor and the Space Structuring Model", Metphor and Symbol, 16, pp. 295-316.

DICCIONARIO DE USO DEL ESPAÑOL DE AMÉRICA Y ESPAÑA. (2003): VOXUSO, Barcelona: SPES Editorial.

DOMĖNECH BAGARIA, O, Y ESTOPÀ BAGOT, R. (2011): "La neologia per sufixació: anàlisi contrastiva entre varietats diatòpiques de la llengua catalana", Caplletra. Revista Internacional de Filologia, 51, pp. 9-33.

FAUCONNIER, G. ([1985] (1994)): Mental Spaces: Aspects of Meaning Construction in Natural, Cambridge: Cambridge University Press.

FAUCONNIER, G. (1997): Mappings in Thought and Language, Cambridge: Cambridge University Press.

FAUCONNIER, G. \& TURNER, M. (2001): "Conceptual Integration Networks", Cognitive Science, 22, pp. 133-187.

FELÍU ARQUIOLA, E. (2009). Palabras con estructura interna: En E. De Miguel. (ed.), Panorama de la lexicología, Barcelona: Ariel (§ 2, primera parte), pp. 51-80.

FUENTES MORRISON, M, GERDING SALAS, C, PECCHI SÁNCHEZ, A, KOTZ GRABOLE, G Y CAÑETE GONZÁLEZ, P. (2009): "Neología léxica: reflejo de la vitalidad del español de chile", Revista de Lingüistica Teórica y Aplicada, 47, pp. 103-124.

GIRALDO OSORIO, J. (2016): "La neologia: indicador de la vitalidad de una lengua y su cultura", Revista Interamericana de Bibliotecología, 39, pp. 3946.

GRADY, J., OAKLEY, T. Y COULSON, S. (1999): Blending and Metaphor: En G. Steen y R. Gibbs (Eds). Metaphor in Cognitive lin- guistics, Filadelfia: John Benjamins. Disponible en: http:/ / markturner.org/blendaphor.html

LANG, M. (1992): Formación de palabras en español. Morfología derivativa productiva en léxico moderno. Madrid: Cátedra

MEYER-LÜBKE, W. (1974): Grammaire des Langues Romanes. Tome II. Morphologie. Réimpression de l'édition de Paris 1890-1906, Marseille: Laffitte Reprints.

MONGE CASAO, F. (1996): "Aspectos de la Sufijación en Español", Revista Española de Lingüistica, 1, pp. 43-56.

PASCUAL OLIVÉ, E. (2012): Los Espacios Mentales y la Integración Conceptual. En I. Ibarretxe-Antañano y J. Valenzuela (Dirs.), Lingüistica Cognitiva, Barcelona: Anthropos Editorial, pp. 147-166.

RAINER, F. (1993). Spanische Wortbildungslebre, Tübingen; Max Niemeyer Verlag.

REAL ACADEMIA ESPAÑOLA. (2014, 23. ${ }^{a}$ ed.): Diccionario de la Lengua Española, Madrid: Espasa.

SANTANA SUÁREZ, O., CARRERA RIUDAVETS, F., PÉREZ AGUIAR, J., \& RODRÍGUEZ RODRÍGUEZ, G. (Eds.), (2005): Una Aplicación para el Procesamiento de la Sufijación en Español. Grupo de Estructuras de Datos y Lingüística Computacional, Universidad de las Palmas de Gran Canaria, España.

SANTIAGO LACUESTA, R. Y BUSTOS GISBERT, E. (1999): La derivación nominal. En I. Bosque y V. Demonte (eds.), Gramática descriptiva de la lengua española, Madrid: Espasa Calpe, pp. 4505-4643.

TURNER, M. \& FAUCONNIER, G. (1998): "Metaphor, Metonymy and Binding": En A. Barcelona 
(Ed.), Metonymy and Metaphor, Berlin: Mouton de Gryter, pp. 133-145.

VALLĖS BOTEY, T. (2002): La productividad morfológica en un modelo dinámico basado en el uso y en los usuarios. En M. T. Cabré, J. Freixa y E. Solé. (Eds.), Lexic i Neologia, Barcelona: Observatori de Neologia. Institut Universitari de Lingüística Aplicada, Universitat Pompeu Fabra, pp.139-157. 